\title{
ESTUDO SOBRE LUBRIFICAÇÃO EM ROLAMENTOS E DESENVOLVIMENTO DE UM TRIBÔMETRO MÉTODO REICHERT ${ }^{1}$
}

LUBRICATION'S STUDY ABOUT BEARINGS AND DEVELOPMENT OF A TRIBOMETER REICHERT METHOD

Recebimento:16/11/2017- Aceite: 09/01/2018- Publicação: 28/01/2018

Processo de Avaliação: Double Blind Review

\author{
Alan Mendes de Souza ${ }^{2}$ \\ Graduando em Tecnologia em Manutenção Industrial \\ Faculdade de Tecnologia de Osasco - Fatec Osasco \\ lhp_alan@hotmail.com
}

\section{Fabrício Ap. Ferraz da Silva}

Graduando em Tecnologia em Manutenção Industrial

Faculdade de Tecnologia de Osasco - Fatec Osasco

fabricio.ap.ferraz@hotmail.com

\section{Felipe Amade de Souza}

Graduando em Tecnologia em Manutenção Industrial

Faculdade de Tecnologia de Osasco - Fatec Osasco

felipe.amade@yahoo.com.br

\section{Carlos Humberto Sartori}

Mestre em Engenharia Metalúrgica e Materiais

Faculdade de Tecnologia de Osasco - Fatec Osasco

chsartori80@gmail.com

\section{Carlos Alberto de Freitas}

Engenheiro de Produção

Faculdade de Tecnologia de Osasco - Fatec Osasco

carlos.afreitas@ffatec.sp.gov.br

\section{Antonio Carlos Arruda}

Mestre em Engenharia Elétrica

Faculdade de Tecnologia de Osasco - Fatec - Osasco

antonio.arruda@fatec.sp.gov.br

\footnotetext{
${ }^{1}$ Método Reichert de ensaio sendo cilindro sobre disco.

${ }^{2}$ Autor para correspondência: Faculdade de Tecnologia do Estado de São Paulo, Rua Pedro Rissato, 30, Vila dos

Remédios, Osasco - SP, Brasil - CEP 06296-220.
}

Revista ENIAC Pesquisa, Guarulhos (SP), V.7, n.1, jan.- jun. 2018. 


\section{RESUMO}

O estudo se destina a abordagem das possíveis falhas em elementos de máquinas (rolamentos) fabricados em AISI 52100 e seus principais mecanismos de desgaste sendo adesão, abrasão, corrosão e fadiga. Serão apresentados os principais tipos de lubrificantes, dando ênfase nos óleos e graxas quanto a suas características físico-químicas e seus principais aditivos. Para viabilidade do estudo foi desenvolvido um dispositivo que realizou ensaios em um mesmo lubrificante de viscosidade $15 \mathrm{~W}^{3}-50$ com períodos de utilização distintos sendo estes 1000, 2000 e $3000 \mathrm{~km}$, desta forma foi possível medir o rompimento da película de lubrificação em função da pressão exercida pelo dispositivo e sendo assim exemplificar de maneira efetiva os efeitos danosos aos elementos de máquinas em função da má gestão da lubrificação.

Palavras-Chave: Lubrificação; desgaste; atrito; rolamento; energia.

\section{ABSTRACT}

The study is intended to approach the possible failures in machine elements (bearings) manufactured in AISI 52100 and its main wear mechanisms, adhesion, abrasion, corrosion and fatigue. the main types of lubricants will be presented, with an emphasis on oil and grease characteristics, physico-chemical and its major additives. The study was carried out a device that performed tests in the same $15 \mathrm{~W}$-50 viscosity lubricant at different periods of utilization 1000, 2000 and 3000 kilometers. Iit was possible to measure the breakage of the lubricating film due to the pressure exerted by the device and thus effectively exemplify the adverse effects on machine elements due to the poor management of lubrication.

Keywords: lubrication; wear; friction; bearing; energy.

\section{INTRODUÇÃO}

Com o aumento da competitividade entre as instituições a manutenção vem sendo observada como atividade estratégica para garantir alta competitividade, é imprescindível que se mantenha alta disponibilidade dos ativos e a lubrificação é uma das atividades que garantem essa disponibilidade.

Diversos tipos de problemas são atribuídos a falta de lubrificação ou a má aplicação da mesma. Quando esta falha surge, uma força atuante nos sistemas mecânicos aumenta drasticamente, o atrito que quando elevado aumenta a temperatura dos elementos envolvidos. Os rolamentos são elementos de máquinas que tem a função de favorecer o movimento

\footnotetext{
${ }^{3}$ Abreviação para o termo Winter.
}

Revista ENIAC Pesquisa, Guarulhos (SP), V.7, n.1, jan.- jun. 2018. 
suavizando o mesmo de forma a facilitar a rotação e estão presentes desde sistemas mecânicos complexos a utensílios de nosso cotidiano.

Quando bem aplicada a lubrificação tende a maximizar a vida útil destes componentes aumentando a disponibilidade o desempenho e a qualidade dos ativos no que se refere a produção e manutenção de suas funções. O estudo abordará os tipos de fluídos lubrificantes com foco nos líquidos sendo os óleos e semissólidos compreendidos por graxas lubrificantes. Um dispositivo foi desenvolvido de modo a viabilizar os estudos no que se refere ao cisalhamento da película de lubrificação que será rompida em função de uma carga exercida por um corpo de prova sobre uma ferramenta geradora de atrito (que se encontra recoberta por uma película de lubrificação). Os ensaios foram realizados em fluídos de viscosidade 15W-50 com períodos de utilização distintos sendo estes de 1000, 2000 e $3000 \mathrm{~km}$ rodados. A partir dos resultados foram determinados os efeitos danosos aos sistemas mecânicos quando a lubrificação não é realizada de forma correta, o que implica na indisponibilidade dos ativos e paradas não planejadas.

\section{METODOLOGIA}

O fluído que foi submetido ao ensaio é um óleo lubrificante multiviscoso $15 \mathrm{~W}-50$ de base semissintética e este atende as exigências dos organismos certificadores JASO ${ }^{4}$ e $\mathrm{API}^{5}$. O fluído foi submetido ao trabalho em um motor de combustão interna com refrigeração a ar, possui 125 cilindradas e $13 \mathrm{CV}^{6}$ de potência a um regime de rotação de $8500 \mathrm{rpm}^{7}$ como informado pelo fabricante.

O motor foi submetido a um regime de utilização, atuando como meio de transporte e locomoção. As quilometragens referentes aos testes serão marcadas no próprio painel, indicando a quilometragem inicial e final, é informado pelo fabricante do fluído lubrificante que o mesmo é recomendado para até $2000 \mathrm{~km}$ rodados de utilização.

O teste tem por objetivo analisar a resistência da película de lubrificação hidrodinâmica, que será formada pelo dispositivo, e analisar o fluído lubrificante em ensaios distintos em função de sua utilização, sendo estas $1000 \mathrm{~km}, 2000 \mathrm{~km}$ e $3000 \mathrm{~km}$ rodados e fazer o comparativo dos resultados obtidos entre os ensaios, e o comparativo com um fluído

\footnotetext{
${ }^{4}$ JASO- Abreviação para o termo Japanese Automotive Standarts Organization.

${ }^{5}$ API- Abreviação para o termo American Petroleum Institute.

${ }^{6} \mathrm{CV}$ - Abreviação para o termo Cavalo Vapor.

${ }^{7} \mathrm{Rpm}$ - Abreviação para o termo Rotações por minuto.
}

Revista ENIAC Pesquisa, Guarulhos (SP), V.7, n.1, jan.- jun. 2018. 
lubrificante novo sem utilização. E desta forma, demonstrar os efeitos da má gestão da lubrificação ou de sua má aplicação aos conjuntos mecânicos e elementos de máquinas tais como rolamentos ou mancais de deslizamento, e a forma ou quais as possíveis falhas podem ocorrer provenientes da negligência na lubrificação.

O teste possui quatro variáveis sendo estas, carga, tempo, rotação e volume de lubrificante. A carga foi obtida por meio de um dispositivo que funciona a partir do princípio de Arquimedes respeitando a capacidade com relação aos limites de corrente elétrica do motor e inversor de frequência, garantindo desta forma a integridade de ambos. O tempo foi determinado de modo que o corpo de prova não atinja desgaste tão severo. A rotação foi determinada de modo que haja a formação de uma película de lubrificação por toda a ferramenta geradora de atrito sem que haja o derramamento para fora do cárter. O volume foi estipulado de modo a produzir a película por sobre a ferramenta geradora de atrito, e que mantivesse um volume considerável para a manutenção da mesma.

Sendo assim a carga foi estabelecida em 52,40N, com tempo de duração de 240 segundos, com rotação de 450 rpm e volume de $20 \mathrm{ml}$ de fluído lubrificante.

Para cada fluído lubrificante foram utilizados três corpos de provas confeccionados em AISI 52100 com dureza entre 58 - 63 HRC todos os corpos de provas foram pesados em balança analítica $^{8}$, os corpos de prova foram submetidos a uma nova pesagem após os ensaios, para que desta forma fosse determinado a perda de massa que cada corpo de prova sofreu em função do atrito.

\section{FUNDAMENTAÇÃO TEÓRICA}

Tribologia é uma palavra que vem do grego, tribos tem o significado de atritar friccionar e logos que significa estudo. Por definição tribologia é a ciência e tecnologia de superfícies interagindo entre se e tecnologias correlacionadas.

A tribologia possui duas vertentes de estudos uma em que se deseja minimizar o atrito ao máximo a fim de, minimizar ao máximo esta força atuante e outra onde o objetivo é atingir o máximo de atrito tanto para acelerações, desacelerações ou manutenção de velocidade. A tribologia é uma ciência que vem sendo praticada bem antes das definições que hoje conhecemos, pois, o homem já obtinha o fogo atritando dois pedaços de madeira um contra o outro, pinturas rupestres egípcias também demonstram que o homem já utilizava a

${ }^{8}$ Balança analítica de precisão modelo SHIMADZU AUW- 220.

Revista ENIAC Pesquisa, Guarulhos (SP), V.7, n.1, jan.- jun. 2018. 
tribologia naquele período, adicionado uma substância entre a estátua e o solo com o intuito de minimizar o atrito e desta forma facilitar o transporte da mesma.

\subsection{SISTEMAS TRIBOLÓGICOS}

Segundo Gahr (1987), no entendimento dos sistemas tribológicos é importante destacar que estes são representados por quatro elementos sendo estes, corpo sólido, contra corpo, elemento interfacial e ambiente. O contra corpo pode ser um líquido um sólido um gás ou a mistura entre estes o elemento interfacial pode ser um lubrificante uma camada adsorvida de óxidos ou até mesmo sujeira vindo de fora para dentro do sistema. E podemos ter uma grande variação de interações sendo estas, rolamento, impacto, oscilatório impacto erosivo etc.

\subsubsection{Atrito}

Segundo Telles e Mongelli Netto (2014), atrito é uma força que surge sempre que dois corpos entram em contato e interagem entre-se, as protuberâncias (irregularidades) das superfícies dos corpos que estão em contato, que são responsáveis pelo atrito, e esta força aumenta proporcionalmente à medida em que se aumenta a velocidade de interação entre os corpos e a pressão que estes estão submetidos. A força de atrito sempre está no sentido contrário ao movimento e graças a esta força que somos capazes de realizar tarefas do cotidiano tais como caminhar, quando caminhamos a força de atrito está atuando no sentido contrário ao deslocamento. Existem dois tipos de atrito o atrito estático e o atrito cinético quando o corpo se encontra em repouso este está sujeito a força de atrito estático no momento em que ocorre um desequilíbrio das forças e o movimento passa existir o atrito deixa de ser estático e passa a ser um atrito cinético ambos os atritos são representados pela letra grega $\mu$ e é entendido que quando não há movimento a força de atrito é máxima sendo assim:

$$
\begin{aligned}
& \text { Fate }=\boldsymbol{\mu}_{\mathbf{e}} \times \mathbf{N}>\mathbf{F} \mathbf{a t}=\boldsymbol{\mu} \times \mathbf{N} \\
& \mathbf{F} \text { ate }=\text { Força de atrito estático } \\
& \mathbf{F a t}=\text { Força de atrito } \\
& \boldsymbol{\mu}=\text { Coeficiente de atrito (estático ou cinético) } \\
& \mathbf{N}=\text { Força normal }
\end{aligned}
$$

Revista ENIAC Pesquisa, Guarulhos (SP), V.7, n.1, jan.- jun. 2018. 
Esta força é de fundamental importância como acima descrito, porém em alguns sistemas como, mancais de deslizamento, rolamentos e engrenagens esta força deve ser minimizada ao máximo com o intuito de maximizar a vida útil dos elementos de máquinas e conjuntos mecânicos.

\subsubsection{Mecanismos de desgaste}

\subsubsection{Adesão}

Segundo Gahr (1987), o desgaste de adesão ocorre quando a força de adesão é superior a força de deslizamento, envolve alta pressão e o contato real entre as superfícies. A rugosidade na área de contato em função da alta pressão pode provocar o micro caldeamento entre os picos e quando ocorrer o movimento este se rompem fazendo a retirada de material de uma superfície, para a outra.

\subsubsection{Abrasão}

Segundo Gahr (1987), desgaste abrasivo é a perda de material pela passagem de partículas rígidas por sobre uma superfície sólida, este desgaste aumenta em função da pressão e da velocidade relativa do movimento entre as superfícies em contato. O desgaste abrasivo pode ser de dois ou três corpos.

\subsubsection{Fadiga}

Segundo Gahr (1987), desgaste por fadiga em superfície pode ser caracterizado por formação de trincas e esfoliação do material ocasionado por carregamentos cíclicos repetidos e alternados. A interação entre sólidos como por exemplo, o deslizamento ou o impacto entre líquidos e sólidos resulta em tensão na superfície que podem produzir fadiga localizada.

\subsubsection{Corrosão}

Segundo Usberco e Salvador (2010), corrosão é o processo de deterioração dos metais, este processo também é conhecido como oxirredução, envolve o ganho e a perda de elétrons sendo de uma forma genérica o elemento que oxida perde elétrons e o elemento que reduz recebe elétrons esse fenômeno é conhecido como reação eletroquímica. Existem diversos tipos de corrosão sendo os mais estudados, corrosão uniforme, corrosão localizada, corrosão por pite, corrosão por fenda entre outros.

Revista ENIAC Pesquisa, Guarulhos (SP), V.7, n.1, jan.- jun. 2018. 


\title{
3.2. LUBRIFICAÇÃO
}

Lubrificação é uma atividade que consiste em introduzir uma substância entre duas superfícies que estão em movimento relativo entre si, tem por finalidade lubrificar, reduzir atrito, proteger contra oxidação e trocar calor. Normalmente as substâncias adicionadas ao sistema são óleos e graxas lubrificantes. Dentre os sistemas de lubrificação temos lubrificação hidrodinâmica, elastohidrodinâmica, limítrofe e mista.

\subsection{ROLAMENTO}

\begin{abstract}
Segundo Armini e Saulo (1996, p.54), os rolamentos são elementos de máquinas de suma importância nos sistemas mecânicos, estes elementos são responsáveis pela redução do atrito nos sistemas tanto em baixa ou alta rotação. Os rolamentos são compostos basicamente de dois anéis metálicos esferas ou roletes que são separadas por gaiola ou separadores, usualmente os rolamentos são confeccionados pelo (SAE 52100). (Armini; Saulo, 2002).
\end{abstract}

O material de fabricação dos rolamentos se trata do SAE 52100, aço de médias liga que em sua composição química apresenta $\mathrm{Fe}, \mathrm{C}, \mathrm{Cr}, \mathrm{Mn}$, e Si. Em função do alto teor de carbono presente neste aço, temos um grande teor de carbonetos metálicos, sendo majoritariamente, carboneto de cromo $\mathrm{Cr}_{3} \mathrm{C}_{2}$ e carboneto de ferro $\mathrm{Fe}_{3} \mathrm{C}$, estes compostos são de extrema dureza muito superior a matriz metálica que neste aço se trata da estrutura martensítica. O tratamento térmico é uma importante etapa no processo de fabricação dos rolamentos, pois precisa garantir a homogeneidade de dureza entre as peças envolvidas dureza esta que nos rolamentos atua na faixa de 58 a $62 \mathrm{HRC}$.

\section{APRESENTAÇÃO DO PROJETO E ANÁLISE DE RESULTADOS}

O equipamento foi construído com o objetivo de medir o cisalhamento de uma película de lubrificação hidrodinâmica a partir da força exercida por um conjunto mecânico baseado no método Reichert, que consiste em cilindro e disco metálico, um contra o outro, conforme figuras 1 e 2 , com o intuito de avaliar cisalhamento de uma película de lubrificação em função de uma força exercida sobre a mesma.

Revista ENIAC Pesquisa, Guarulhos (SP), V.7, n.1, jan.- jun. 2018. 


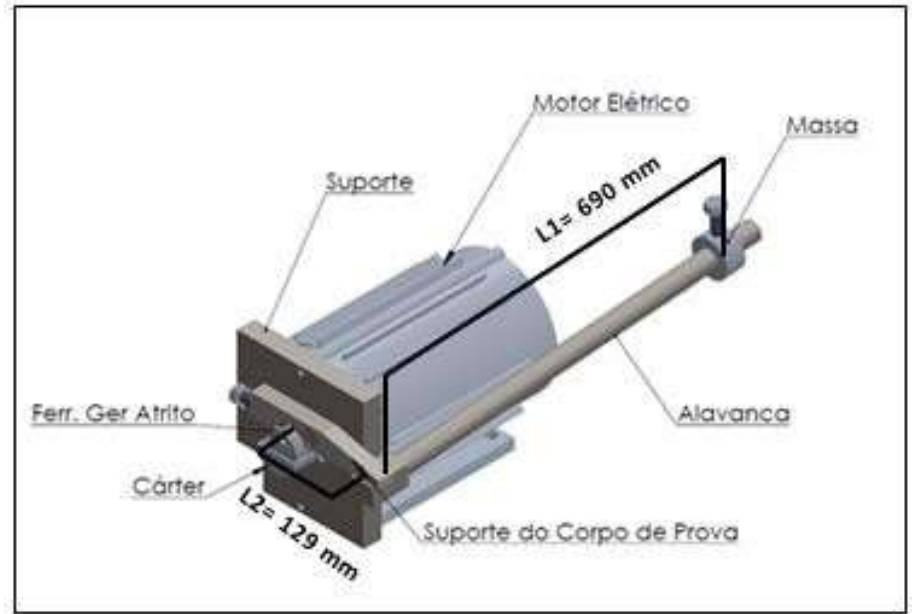

Fonte: Autores, 2017.

Figura 2: Método Reichert

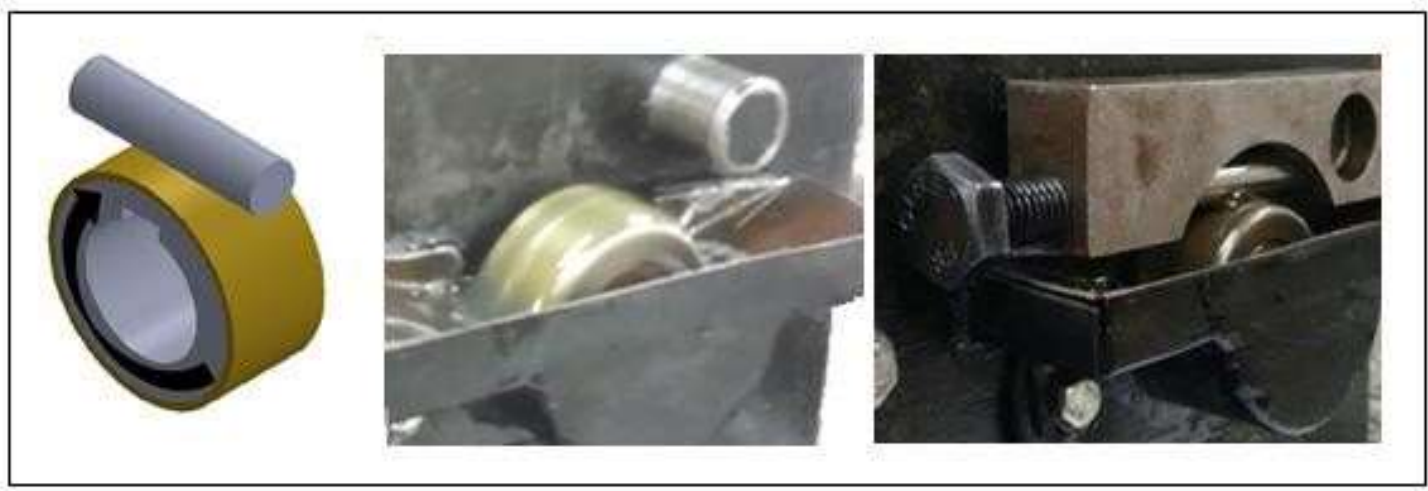

Fonte: Autores, 2017.

O equipamento foi construído com o intuito de avaliar o desempenho de fluídos lubrificantes em função de sua utilização que neste trabalho é abordado em quilômetros rodados. O equipamento foi construído pelos autores e o mesmo possui três sistemas.

- $\quad$ Sistema de sustentação composto por uma bancada confeccionada em aço AISI 1020 utilizando se do processo de soldagem MIG.

- $\quad$ Sistema mecânico composto por um suporte, alavanca, massas, suporte do corpo de provas, cárter, e ferramenta geradora de atrito esta foi confeccionada em aço AISI 1020 e passou por um tratamento termoquímico de cementação gasosa com o intuito de atingir máxima dureza, após o tratamento a peça passou de uma dureza de $180 \mathrm{HB}$ para $62 \mathrm{HRC}$ profundidade $1,2 \mathrm{~mm}$.

Revista ENIAC Pesquisa, Guarulhos (SP), V.7, n.1, jan.- jun. 2018. 
- $\quad$ Sistema elétrico composto de um motor elétrico de $2 \mathrm{CV}$ de potência, tensão trifásica de $220 \mathrm{~V}$ quatro polos e um inversor de frequência. ${ }^{9}$

Todos os corpos de prova foram submetidos ao ensaio como descrito, seguindo todos os critérios e respeitando os valores de variáveis para cada corpo de prova e fluído lubrificante.

Figura 3: Desgastes nos corpos de prova

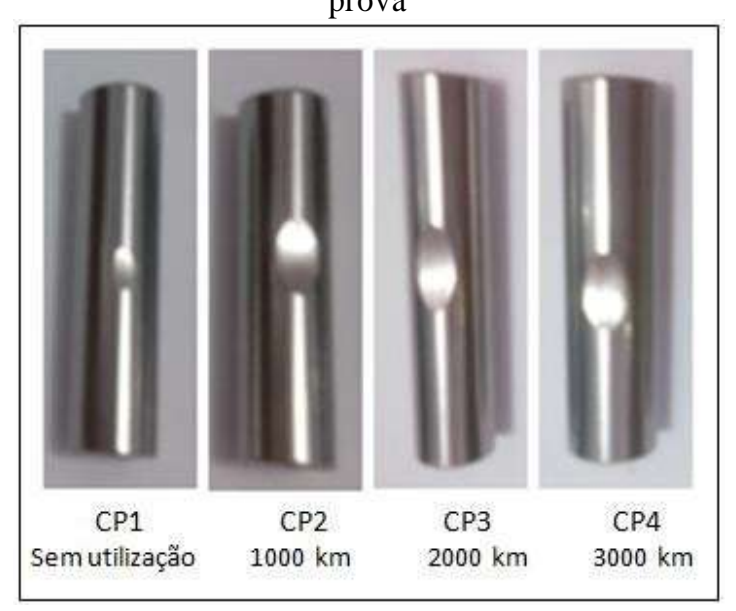

Fonte: Autores, 2017.

A seguir são expressos os valores de perda em massa para cada corpo de prova descritos nas tabelas 1 a 4, os valores do consumo de corrente elétrica em função do atrito para cada corpo de prova e fluídos lubrificantes nas tabelas 5 a 8 porém os resultados do consumo de corrente elétrica são informativos e não conclusivos.

Tabela 1: Fluído 15W- 50 sem utilização, massa inicial e final

\begin{tabular}{ccc}
\hline Corpos de Prova & Massa Inicial $(\mathrm{g})$ & Massa Final $(\mathrm{g})$ \\
\hline $\mathrm{CP} 1 \mathrm{~N}^{\circ} 1$ & 24,3654 & 24,3599 \\
$\mathrm{CP} 1 \mathrm{~N}^{\circ} 2$ & 24,3698 & 24,3618 \\
$\mathrm{CP} 1 \mathrm{~N}^{\circ} 3$ & 24,3771 & 24,3721
\end{tabular}

Fonte: Autores, 2017.

${ }^{9}$ Modelo CFW - 08 de marca Weg.

Revista ENIAC Pesquisa, Guarulhos (SP), V.7, n.1, jan.- jun. 2018. 
Tabela 2: Fluído 15W- 50 com 1000 km rodados, massa inicial e final

\begin{tabular}{ccc}
\hline Corpos de Prova & Massa Inicial $(\mathrm{g})$ & Massa Final $(\mathrm{g})$ \\
\hline $\mathrm{CP} 2 \mathrm{~N}^{\circ} 1$ & 24,3737 & 24,2839 \\
$\mathrm{CP} 2 \mathrm{~N}^{\circ} 2$ & 24,3699 & 24,3009 \\
$\mathrm{CP} 2 \mathrm{~N}^{\circ} 3$ & 24,3824 & 24,2889
\end{tabular}

Fonte: Autores, 2017.

Tabela 3: Fluído 15W- 50 com 2000 km rodados, massa inicial e final

\begin{tabular}{ccc}
\hline Corpos de Prova & Massa Inicial $(\mathrm{g})$ & Massa Final $(\mathrm{g})$ \\
\hline $\mathrm{CP} 3 \mathrm{~N}^{\circ} 1$ & 24,3672 & 24,2584 \\
$\mathrm{CP} 3 \mathrm{~N}^{\circ} 2$ & 24,3705 & 24,2635 \\
$\mathrm{CP} 3 \mathrm{~N}^{\circ} 3$ & 24,3718 & 24,2656
\end{tabular}

Fonte: Autores, 2017.

Tabela 4: Fluído 15W- 50 com 3000 km rodados, massa inicial e final

\begin{tabular}{ccc}
\hline Corpos de Prova & Massa Inicial $(\mathrm{g})$ & Massa Final $(\mathrm{g})$ \\
\hline $\mathrm{CP} 4 \mathrm{~N}^{\circ} 1$ & 24,3730 & 24,2992 \\
$\mathrm{CP} 4 \mathrm{~N}^{\circ} 2$ & 24,3804 & 24,2573 \\
$\mathrm{CP} 4 \mathrm{~N}^{\circ} 3$ & 24,3775 & 24,2565
\end{tabular}

Fonte: Autores, 2017.

Tabela 5: Corrente elétrica em função do atrito, fluído $15 \mathrm{~W}$ - 50 sem utilização

\begin{tabular}{ccc}
\hline Corpos de Provas & $\begin{array}{c}\text { Corrente do motor sem } \\
\text { carga (A) }\end{array}$ & $\begin{array}{c}\text { Corrente do motor } \\
\text { com carga (A) }\end{array}$ \\
\hline $\mathrm{CP} 1 \mathrm{~N}^{\circ} 1$ & $3,20-3,28$ & $3,76-3,99$ \\
$\mathrm{CP} 1 \mathrm{~N}^{\circ} 2$ & $3,20-3,28$ & $3,70-3,97$ \\
$\mathrm{CP} 1 \mathrm{~N}^{\circ} 3$ & $3,20-3,28$ & $3,72-3,95$ \\
\hline
\end{tabular}

Fonte: Autores, 2017.

Tabela 6: Corrente elétrica em função do atrito, fluído 15W- 50 com 1000 km rodados

\begin{tabular}{ccc}
\hline Corpos de Provas & $\begin{array}{c}\text { Corrente do motor sem carga } \\
(\mathrm{A})\end{array}$ & $\begin{array}{c}\text { Corrente do motor } \\
\text { com carga (A) }\end{array}$ \\
\hline $\mathrm{CP} 2 \mathrm{~N}^{\circ} 1$ & $3,20-3,28$ & $3,93-4,16$ \\
$\mathrm{CP} 2 \mathrm{~N}^{\circ} 2$ & $3,20-3,28$ & $3,76-4,20$ \\
$\mathrm{CP} 2 \mathrm{~N}^{\circ} 3$ & $3,20-3,28$ & $3,77-4,19$ \\
\hline
\end{tabular}

Fonte: Autores, 2017.

Revista ENIAC Pesquisa, Guarulhos (SP), V.7, n.1, jan.- jun. 2018. 
Tabela 7: Corrente elétrica em função do atrito, fluído 15W- 50 com 2000 km rodados

\begin{tabular}{ccc}
\hline $\begin{array}{c}\text { Corpos de } \\
\text { Provas }\end{array}$ & $\begin{array}{c}\text { Corrente do motor sem carga } \\
(\mathrm{A})\end{array}$ & $\begin{array}{c}\text { Corrente do motor } \\
\text { com carga (A) }\end{array}$ \\
\hline $\mathrm{CP} 3 \mathrm{~N}^{\circ} 1$ & $3,20-3,28$ & $3,89-4,08$ \\
$\mathrm{CP} 3 \mathrm{~N}^{\circ} 2$ & $3,20-3,28$ & $3,82-4,80$ \\
$\mathrm{CP} 3 \mathrm{~N}^{\circ} 3$ & $3,20-3,28$ & $3,87-4,77$ \\
\hline
\end{tabular}

Fonte: Autores, 2017.

Tabela 8: Corrente elétrica em função do atrito, fluído 15W- 50 com $3000 \mathrm{~km}$ rodados

\begin{tabular}{ccc}
\hline $\begin{array}{c}\text { Corpos de } \\
\text { Provas }\end{array}$ & $\begin{array}{c}\text { Corrente do motor sem carga } \\
(\mathrm{A})\end{array}$ & $\begin{array}{c}\text { Corrente do motor com } \\
\text { carga }(\mathrm{A})\end{array}$ \\
\hline $\mathrm{CP} 4 \mathrm{~N}^{\circ} 1$ & $3,20-3,28$ & $3,80-4,17$ \\
$\mathrm{CP} 4 \mathrm{~N}^{\circ} 2$ & $3,20-3,28$ & $3,78-4,23$ \\
$\mathrm{CP} 4 \mathrm{~N}^{\circ} 3$ & $3,20-3,28$ & $3,83-4,20$
\end{tabular}

Fonte: Autores, 2017.

As tabelas 9 a 12 demonstram o desgaste dos corpos de provas submetidos, ao teste e possibilita comparar a perda de massa entre os corpos de prova, em função do atrito proveniente da utilização dos fluídos dada em quilômetros, sendo o fluído padrão sem utilização e os fluídos submetidos a trabalho com quilometragens de 1000, 2000 e $3000 \mathrm{~km}$ rodados.

Tabela 9: Perda de massa corpos de provas, fluído 15W- 50 sem utilização

\begin{tabular}{ccccc}
\hline Corpos de Provas & Massa Inicial $(\mathrm{g})$ & Massa Final $(\mathrm{g})$ & Diferença $(\mathrm{g})$ & $\begin{array}{c}\text { Diferença } \\
\text { em \% }\end{array}$ \\
\hline $\mathrm{CP} 1 \mathrm{~N}^{\circ} 1$ & 24,3654 & 24,3599 & $-0,0055$ & $-0,6$ \\
$\mathrm{CP} 1 \mathrm{~N}^{\circ} 2$ & 24,3698 & 24,3618 & $-0,008$ & $-0,8$ \\
$\mathrm{CP} 1 \mathrm{~N}^{\circ} 3$ & 24,3771 & 24,3721 & $-0,005$ & $-0,5$ \\
\hline
\end{tabular}

Fonte: Autores, 2017.

Tabela 10: Perda de massa corpos de provas, fluído $15 \mathrm{~W}$ - 50 com $1000 \mathrm{~km}$ rodados

\begin{tabular}{ccccc}
\hline Corpos de Provas & Massa Inicial $(\mathrm{g})$ & Massa Final (g) & Diferença (g) & $\begin{array}{c}\text { Diferença } \\
\text { em \% }\end{array}$ \\
\hline $\mathrm{CP} 2 \mathrm{~N}^{\circ} 1$ & 24,3737 & 24,2839 & $-0,0898$ & $-9,0$ \\
$\mathrm{CP} 2 \mathrm{~N}^{\circ} 2$ & 24,3699 & 24,3009 & $-0,069$ & $-6,9$ \\
$\mathrm{CP} 2 \mathrm{~N}^{\circ} 3$ & 24,3824 & 24,2889 & $-0,0935$ & $-9,3$ \\
\hline
\end{tabular}

Fonte: Autores, 2017.

Revista ENIAC Pesquisa, Guarulhos (SP), V.7, n.1, jan.- jun. 2018. 
Tabela 11: Perda de massa corpos de provas, fluído 15W- 50 com 2000 km rodados

\begin{tabular}{ccccc}
\hline $\begin{array}{c}\text { Corpos de } \\
\text { Provas }\end{array}$ & $\begin{array}{c}\text { Massa Inicial } \\
(\mathrm{g})\end{array}$ & Massa Final $(\mathrm{g})$ & Diferença $(\mathrm{g})$ & $\begin{array}{c}\text { Diferença } \\
\text { em \% }\end{array}$ \\
\hline $\mathrm{CP} 3 \mathrm{~N}^{\circ} 1$ & 24,3672 & 24,2584 & $-0,1088$ & $-10,9$ \\
$\mathrm{CP} 3 \mathrm{~N}^{\circ} 2$ & 24,3705 & 24,2635 & $-0,107$ & $-10,7$ \\
$\mathrm{CP} 3 \mathrm{~N}^{\circ} 3$ & 24,3718 & 24,2656 & $-0,1062$ & $-10,6$ \\
\hline
\end{tabular}

Fonte: Autores, 2017.

Tabela 12: Perda de massa corpos de provas, fluído 15W- 50 com 3000 km rodados

\begin{tabular}{ccccc}
\hline $\begin{array}{c}\text { Corpos de } \\
\text { Provas }\end{array}$ & $\begin{array}{c}\text { Massa Inicial } \\
(\mathrm{g})\end{array}$ & Massa Final $(\mathrm{g})$ & Diferença $(\mathrm{g})$ & $\begin{array}{c}\text { Diferença em } \\
\%\end{array}$ \\
\hline $\mathrm{CP} 4 \mathrm{~N}^{\circ} 1$ & 24,3730 & 24,2992 & $-0,0738$ & $-7,4$ \\
$\mathrm{CP} 4 \mathrm{~N}^{\circ} 2$ & 24,3804 & 24,2573 & $-0,1231$ & $-12,3$ \\
$\mathrm{CP} 4 \mathrm{~N}^{\circ} 3$ & 24,3775 & 24,2565 & $-0,121$ & $-12,1$ \\
\hline
\end{tabular}

Fonte: Autores, 2017.

O gráfico 1 demonstra a perda de massa dos corpos de provas e permite um comparativo entre os mesmos no que se refere a utilização do fluído lubrificante.

Gráfico 1: Perda de massa em corpos de provas

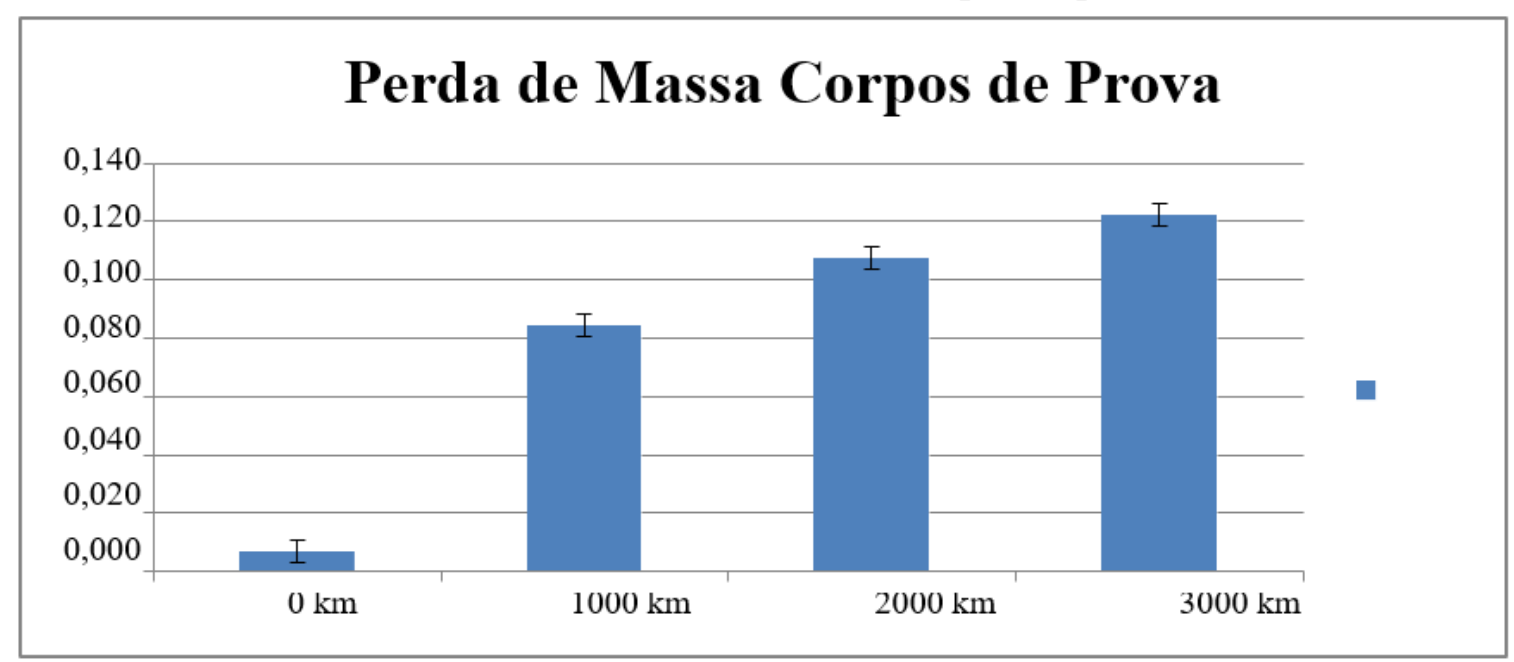

Fonte: autores, 2017.

Os testes demonstraram que todos os corpos de prova tiveram um decréscimo em sua massa em função do atrito, porém, os fluídos lubrificantes com quilometragens de 2000 e 3000 km demonstraram uma perda de massa acentuada, se comparados com o fluído padrão e o fluído lubrificante com utilização de $1000 \mathrm{~km}$ rodados.

Revista ENIAC Pesquisa, Guarulhos (SP), V.7, n.1, jan.- jun. 2018. 
Este desgaste se deu em função da perda das propriedades dos fluídos lubrificantes, no que se refere a degradação do mesmo e a perda de seus aditivos, o que muda drasticamente as características físicas e químicas dos fluídos lubrificantes, com a perda dos aditivos os fluídos lubrificantes se oxidam facilmente e quanto maior for a temperatura maior será a velocidade da oxidação. Com a perda dos aditivos tais como extrema pressão, modificadores de viscosidade, antiespumante e antidesgaste o fluído perde a capacidade de exercer de forma eficiente suas funções tais como lubrificar, reduzir o atrito, proteger contra oxidação e trocar calor, quando o fluído lubrificante deixa de executar estas funções, ou as executa de forma ineficiente temos por consequência o aumento do atrito no sistema mecânico. Na degradação do fluído lubrificante ocorre à formação de outros compostos tais como éteres, ésteres e ácidos carboxílicos que modificam a viscosidade e o caráter ácido do lubrificante dado em $\mathrm{pH}$, o teste foi realizado com tiras indicadoras de pH que possuem a função de medir acidez ou alcalinidade, esta possuí escala de 0 a 14 sendo que de zero a seis indica o caráter ácido, sete, solução neutra e acima de sete indica caráter básico como informado pelo fabricante.

Figura 4: Tabela e teste fita indicadora de $\mathrm{pH}$

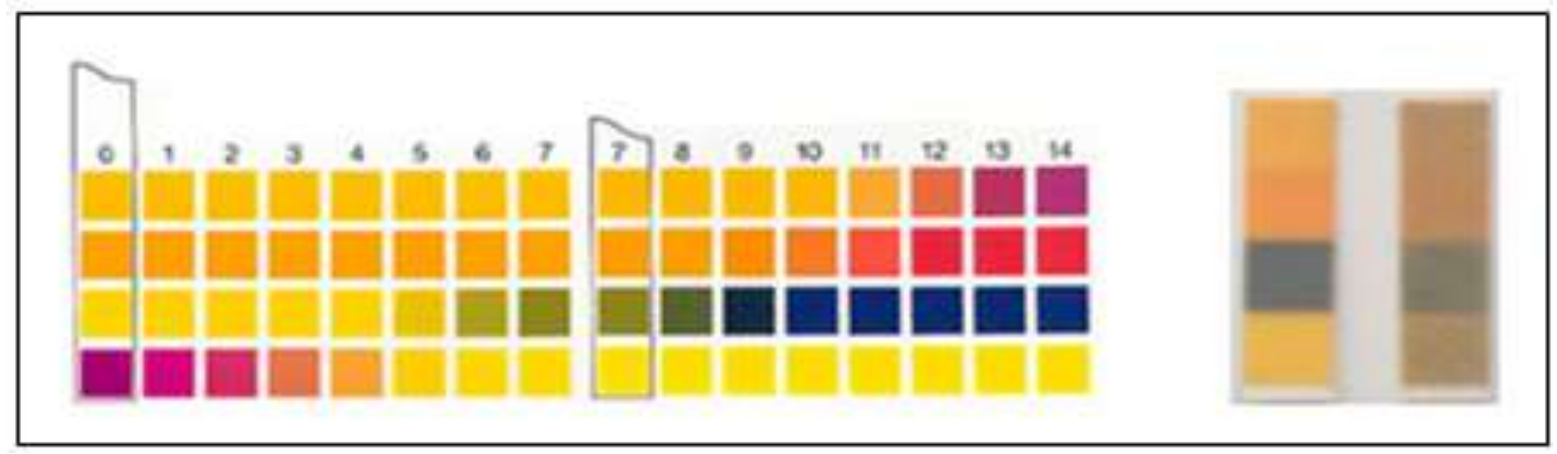

Fonte: Autores, 2017

O teste com fitas indicadoras de $\mathrm{pH}$, só indica a tendência do fluído lubrificante no que se refere a mudança de $\mathrm{pH}$ em função de sua utilização, e por este motivo esta informação é somente informativa

e não conclusiva.

\section{CONSIDERAÇÕES FINAIS}

Os testes realizados demonstraram-se consistentes e coerentes, no que diz respeito a perda de massa dos corpos de provas em função da perda de eficiência dos fluídos lubrificantes, que foram submetidos a trabalho e posteriormente comparados entre si e com o fluído padrão, sendo este sem utilização. Além das perdas de massa o teste foi capaz de demonstrar o acréscimo no valor da corrente elétrica, esta variável no trabalho foi medida de modo a demonstrar a tendência do acréscimo

Revista ENIAC Pesquisa, Guarulhos (SP), V.7, n.1, jan.- jun. 2018. 
no valor de corrente e por este motivo as informações contidas nas tabelas 7 a 10 são somente informativas e não conclusivas.

A máquina construída demonstrou-se eficiente nos testes seguindo os princípios do método Reichert.

Após os testes podemos chegar a alguns direcionamentos no que se refere aos lubrificantes testados, sendo que estes vão perdendo sua eficiência e capacidade de lubrificação em função de sua utilização, degradação e a perda de seus aditivos. O teste teve a capacidade de demonstrar o quão danoso podem ser as perdas nos sistemas mecânicos em função da má gestão ou aplicação da lubrificação.

\section{REFERÊNCIAS}

BELINELLI, M. Desenvolvimento de um Sistema Informatizado Aplicado à Gestão de Planos Preventivos de Lubrificação. 2011. Dissertação de Mestrado em Engenharia de Produção Universidade Tecnológica do Paraná, Paraná, 2011. Disponível em: < http://www.pg.utfpr.edu.br/dirppg/ppgep/dissertacoes/arquivos/162/Dissertacao.pdf >. Acesso em dezembro, 2017.

BELMIRO, P. e CARRETEIRO, R. Lubrificantes e Lubrificação Industrial. Interciência, 2006.

BRUNETI, F. Mecânica dos Fluídos. São Paulo, Pearson Prentice Hall, 2008.

GAHR, H.K Zum. Microestructure and Wear of Materials Elsevier Science Publishers, 1987 (Tradução nossa).

NLGI. National Lubricating Grease Institute, 2016. Disponível em <https://www.nlgi.org/greaseglossary>. Acesso em dezembro, 2017.

NSK, Diagnóstico Rápido de Ocorrência em Rolamentos. 2016. Disponível em : http://nsk.com.br/upload/file/B08.pdf. Acesso em dezembro, 2017.

RADI, Alves.P.et al. Tribologia, Conceitos e Aplicações. Anais do $13^{\circ}$ Encontro de Iniciação Científica e Pós-Graduação do ITA - XIII Encita /2007 ITA, São José dos Campos SP, Brasil, Outubro, 01 a 04, 2007.

SENAI - SERVIÇO NACIONAL DE APRENDIZAGEM INDUSTRIA / CST - COMPANHIA SIDERÚRGICA DE TUBARÃO. Noções Básicas de Elementos de Máquinas - Mecânica. Vitória, CST,1996. Disponível em: 〈http://www.abraman.org.br/arquivos/72/72.pdf>. Acesso em dezembro, 2017.

SERNA, Morelli. Marilene. Quantificação de Carbonetos no Aço Ferramenta AISI/SAE M2. 2008.108f. Tese (Doutorado em Ciência na Área tecnologia Nuclear - Materiais) - Instituto de Pesquisas Energéticas e Nucleares Autarquia Associada á Universidade de São Paulo, São Paulo.

TELLES, D. A. e MONJELLI, J. N. Física com aplicação tecnológica. São Paulo, Blucher, 2011

Revista ENIAC Pesquisa, Guarulhos (SP), V.7, n.1, jan.- jun. 2018. 
USBER CO, J. e SALVADOR, E. Química. São Paulo, Saraiva, 2006.

WEG AS. Manual do Inversos de Frequencia. Disponível em http://ecatalog.weg.net/files/wegnet/1-577.pdf Acesso em dezembro, 2017.

Revista ENIAC Pesquisa, Guarulhos (SP), V.7, n.1, jan.- jun. 2018. 